\title{
Surgical treatment of anterior sternoclavicular dislocation associated with midshaft clavicle fracture: A case report
}

\author{
Philippe Reuter, MD, MSc${ }^{1}$, Kenneth Chen, $\mathrm{MD}^{1}{ }^{1}$, Thomas Klestil, MD, $\mathrm{PhD}^{2}$, \\ Christoph Stotter, MD, PhD²0 \\ ${ }^{1}$ Department of Orthopaedics and Traumatology, Landesklinikum Baden-Mödling, Mödling, Austria \\ ${ }^{2}$ Danube University Krems, Center For Regenerative Medicine, Krems, Austria
}

Concurrent sternoclavicular (SC) joint dislocation and ipsilateral clavicle fracture is a very rare injury with only few cases reported in the literature. ${ }^{[1-4]}$ Even isolated SC dislocations are rare injuries and account for only $3 \%$ of all dislocations around the shoulder. ${ }^{[5]}$ Anterior SC joint dislocations occur nine times more often than posterior SC joint dislocations. Posterior dislocations are often associated with complications such as neurovascular, tracheal or esophageal injuries in up to $30 \%{ }^{[6]}$ and are typically treated surgically. Whether acute anterior SC joint dislocations should be treated conservatively or surgically is still under debate. Sernandez and Riehl $^{[7]}$ found that 38 to $42 \%$ of non-surgically treated anterior SC joint dislocations presented with complications. Conservative treatment shows a redislocation rate varying between 21 and $100 \% .^{[5]}$ The SC joint shows a low congruency between the medial clavicular surface and the manubrial

Received: March 31, 202

Accepted: May 07, 2021

Published online: June 11, 2021

Correspondence: Philippe Reuter, MD. Department of

Orthopaedics and Traumatology, Landesklinikum

Baden-Mödling, 2340 Mödling, Austria.

E-mail: office@dr-reuter.at

Doi: $10.52312 /$ jdrs.2021.135

Citation: Reuter P, Chen K, Klestil T, Stotter C. Surgical treatment of anterior sternoclavicular dislocation associated with midshaft clavicle fracture: A case report. JtDis Relat Surg 2021;32(2):560-565.

(C2021 All right reserved by the Turkish Joint Diseases Foundation

This is an open access article under the terms of the Creative Commons Attribution-NonCommercial License, which permits use, distribution and reproduction in any medium, provided the original work is properly cited and is not used for commercial purposes (http://creativecommons.org/licenses/by-nc/4.0/).

\section{ABSTRACT}

A combination of an anterior sternoclavicular (SC) joint dislocation with a midshaft clavicle fracture is an extremely rare injury. If left untreated, it can lead to severely impaired function of the shoulder with a high risk for complications. A 45-year-old male patient presented with pain and impaired range of motion (ROM) in the left shoulder after a mountain bike crash. Radiographs and a computed tomography scan showed an anterior dislocation of the left SC joint and an ipsilateral midshaft fracture of the clavicle. Open reduction and internal fixation (ORIF) of the clavicle combined with SC joint stabilization using transosseous sutures was performed. Postoperatively, a shoulder-arm bandage was applied with passive motion starting on the first postoperative day. During follow-up, the patient showed an improved clinical function and could return to work after three weeks. Radiographs at eight weeks showed fracture healing without any signs of recurrent SC dislocation. At the final follow-up at 12 weeks, the patient returned to his pre-injury activity level and recreational sports. Despite minimal redislocation in the SC joint, the Constant-Murley Score showed a continuous improvement with $93 \%$, compared to the contralateral side. In conclusion, surgical treatment of anterior SC joint dislocation with a midshaft clavicle fracture can restore shoulder function with no surgery-associated complications.

Keywords: Clavicle fracture, sternoclavicular joint dislocation, surgical treatment.

articular surface. Hence, stability is provided mainly by surrounding ligamentous structures, with the posterior capsule being the most important. ${ }^{[8,9]}$

For surgical treatment of acute SC joint dislocation, various techniques have been described in the literature including transposition of the sternal origin of the sternocleidomastoid, ${ }^{[10]}$ hook plating, ${ }^{[11]}$ and transosseous stabilization using autologous semitendinosus tendon ${ }^{[12]}$ or sutures. ${ }^{[13]}$ So far, no technique has demonstrated superiority over one another. The Kirschner wires should not be used for stabilizing the SC joint, as a high mortality rates have been reported due to wire migration. ${ }^{[14]}$ 
Clavicle fractures, on the other hand, are common accounting for over $4 \%$ of fractures in adults. ${ }^{[15]}$ In younger and active patients, the treatment of midshaft clavicle fractures has shifted toward surgical treatment owing to a decreased incidence of non-union and malunion, compared to non-surgical treatment. ${ }^{[16]}$ In displaced fractures, plate fixation provides more favorable results in pain, function, and cosmetic aspects. ${ }^{[17]}$ However, the decision whether to treat a clavicle fracture surgically or non-surgically should be made on a case-by-case basis, based on the patient's age, comorbidities, and activity level. ${ }^{[18]}$

To the best of our knowledge, there are only four case reports on simultaneous anterior SC joint dislocation and ipsilateral midshaft clavicle fracture reported in the literature over the last 30 years. ${ }^{[1-4]}$ Herein, we present the surgical treatment of anterior SC dislocation associated with a midshaft clavicle fracture which was treated successfully.

\section{CASE REPORT}

A 45-year-old male patient presented to our hospital after a mountain bike accident. He was going downhill and fell on the left shoulder. On clinical examination, the patient had severe pain while testing the active range of motion (ROM) of the shoulder and tingling paresthesia in the left hand with an intact sensitivity. He showed a superficial abrasion over the left shoulder and discomfort to palpation in the middle third of the clavicle. Additionally, the medial clavicle appeared more prominent than the contralateral side and showed vertical instability on palpation. The radiographs showed a minimally displaced midshaft fracture of the left clavicle and a suspected anterior dislocation of the left SC joint (Figure 1). Computed tomography (CT) scans confirmed the diagnosis and showed an anterior SC dislocation without any signs of a neurovascular injury (Figure 1). Initially, the patient was prescribed a sling for immobilization and adequate pain medication.

As a thorough review of the literature provided no clear recommendations on the treatment of such injuries, the patient was offered a surgical treatment, due to his age and activity level. Open reduction and plating of the clavicle combined with open reduction and stabilization of the SC joint would allow early mobilization and a better functional outcome. The patient was informed about the operation including possible risks and complications and other treatment options and a written informed consent was obtained.
The surgery was performed under general anesthesia in the beach chair position. After cutaneous asepsis of the surgical area, anatomical landmarks were marked using a sterile pen. A $20-\mathrm{cm}$ incision from the SC joint to the transition of the middle to lateral third of the clavicle was performed (Figure 2). The clavipectoral fascia was incised to expose the fracture. The subperiosteal preparation of the clavicle to the medial end showed the SC joint anteriorly and superiorly dislocated with an additional rotation component. After exposing the articular surface of the sternum, the articular disc presented undamaged and was left in situ. The shaft fracture of the clavicle showed a short oblique form and was easy to reduce and, therefore, the decision was made to reduce and stabilize the SC joint first. The medial clavicle could be reduced to the articular surface of the sternum using a reduction forceps with serrated jaws. For a figure-of- 8 reconstruction of the SC joint, as described for chronic dislocations, two holes were drilled into the medial clavicle about $10 \mathrm{~mm}$ lateral to the articular surface. ${ }^{[19]}$ Then, two holes were drilled into the manubrium of the sternum, $8 \mathrm{~mm}$ medial to the articular surface. For a stable reconstruction, two 2-mm braided sutures (FiberTape $^{\circledR}$, Arthrex Inc., FL, USA) were shuttled
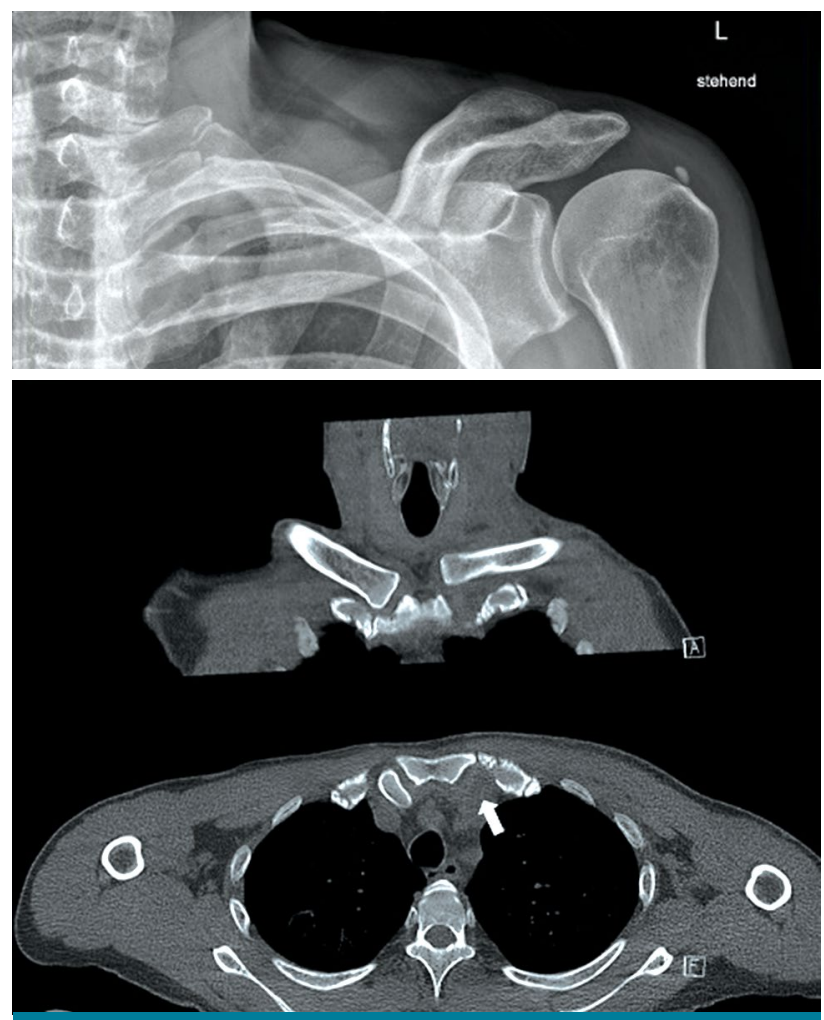

FIGURE 1. Preoperative X-ray and computed tomography scan showing a midshaft clavicle fracture and ipsilateral sternoclavicular dislocation (white arrow). 

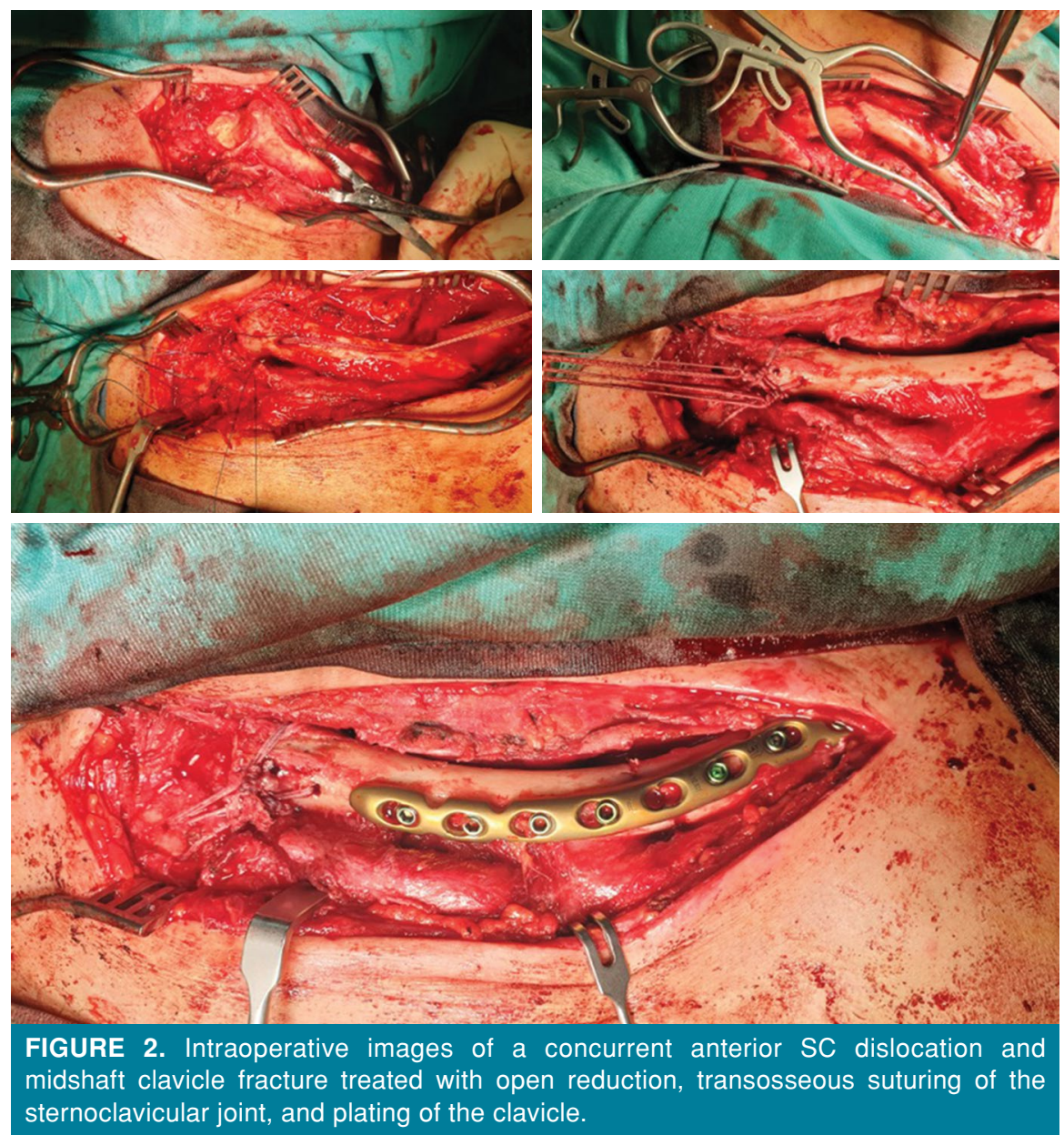

through the holes in a figure-of- 8 pattern and tied. After tightening these first sutures, a slight rotational instability could be observed. To neutralize rotational forces in the SC joint, an additional transosseous suture was placed using a superior drill hole in the medial clavicle $5 \mathrm{~mm}$ lateral to the articular surface. These three sutures provided enough stability with joint congruence. Then, the clavicle midshaft fracture was anatomically reduced and a stable fixation was achieved using a $3.5 \mathrm{~mm}$ locking plate $(3.5 \mathrm{~mm}$ LCP Superior Clavicle Plate, Synthes, Inc., PA, USA). Four bicortical locking screws were inserted medially and three laterally to the fracture. Intraoperative X-rays showed anatomical reduction of both the clavicle and the SC joint with ideal positioning of the plate without any protruding screws. Wound closure was performed after thorough irrigation. A shoulder-arm bandage was applied for postoperative immobilization.

Postoperatively, the patient was admitted to the ward for three days. On the first postoperative day, the patient still reported slight tingling paresthesia in the

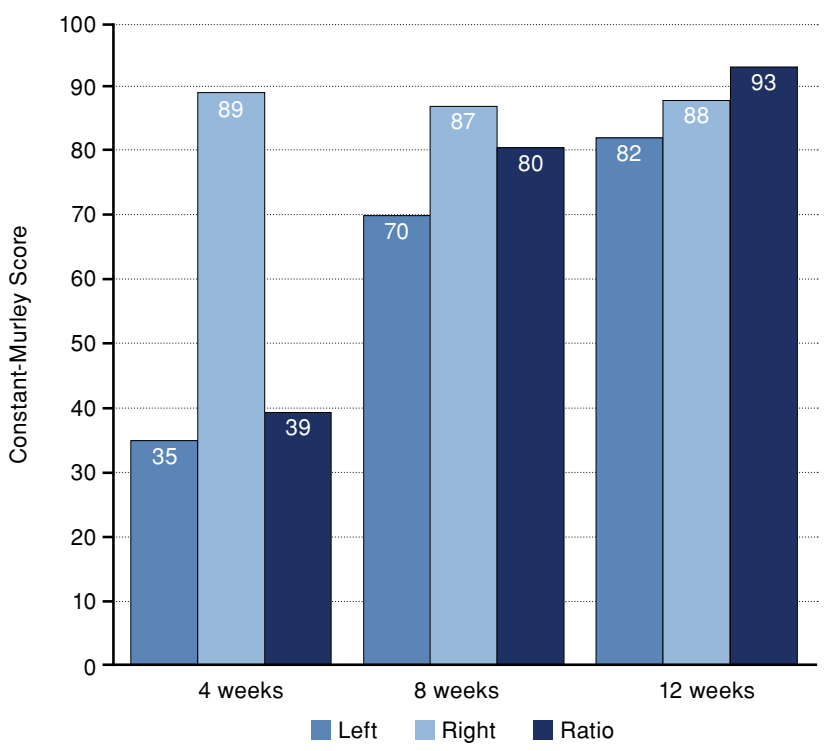

FIGURE 3. Constant-Murley Score at follow-up examinations. The affected left side improved continuously from 4 to 12 weeks postoperatively. 

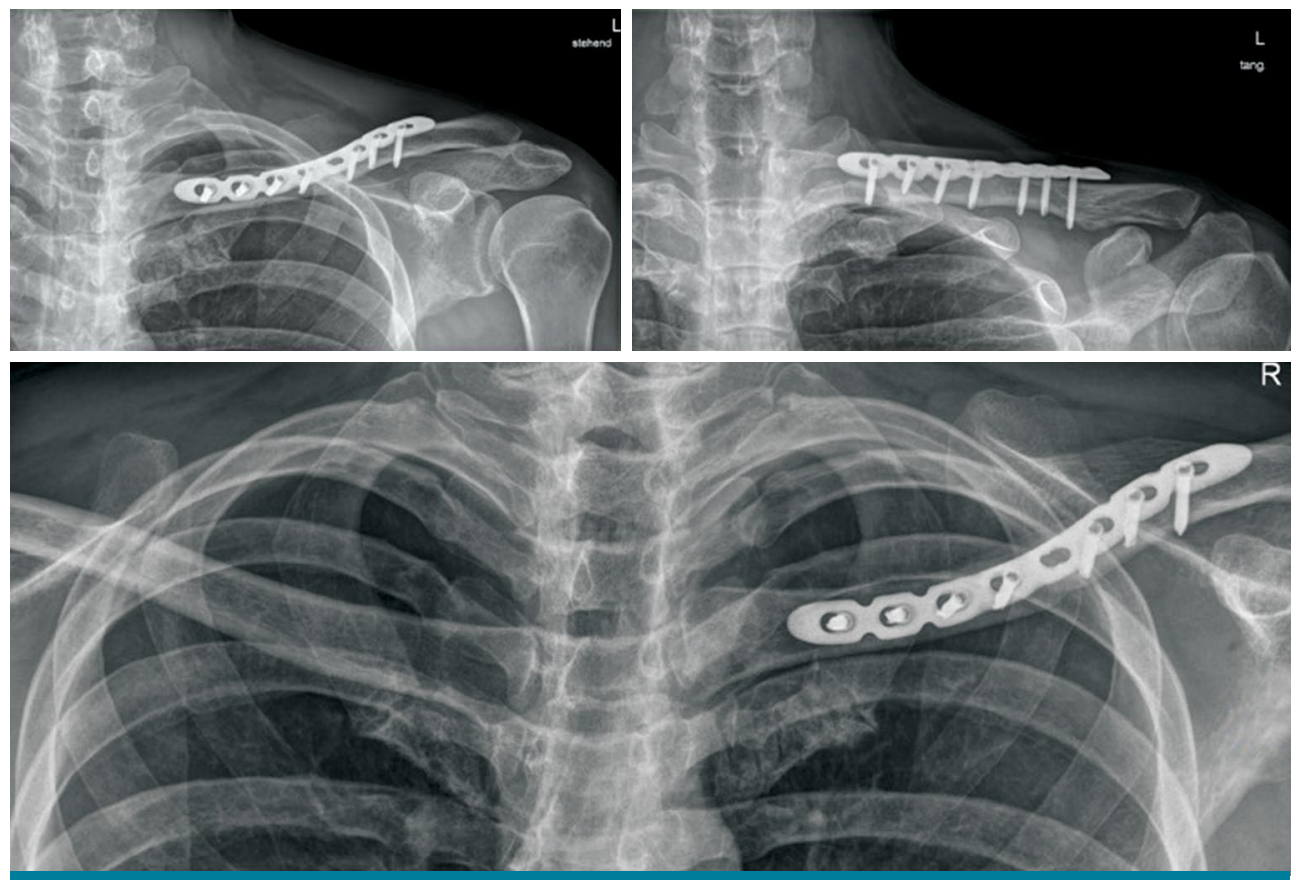

FIGURE 4. X-rays at 12 weeks postoperatively showing complete healing of the midshaft clavicle fracture and satisfactory plate positioning with minimal superior displacement of the medial clavicle.

upright position with resolving in the supine position. A sling was used for six weeks, with physiotherapy with passive swinging motion and continuous passive motion up to $60^{\circ}$ abduction starting on the first postoperative day for four weeks. Passive ROM was continuously increased over the next two weeks, followed by active motion and strengthening exercises starting six weeks after surgery. The surgical wound healed without any complications. The patient could return to work (IT consulting) without any limitations after three weeks. At four weeks of followup, tingling paresthesia fully resolved and active and passive abduction could be performed up to $60^{\circ}$. The Constant-Murley Score (CMS) showed 35/100 points (39\% compared to the unaffected side) (Figure 3) with an apparent decrease in strength and ROM. Shoulder function continuously improved, and fracture healing could be confirmed after eight weeks without any signs of redislocation. Meanwhile, CMS increased to $80 \%$ and the patient was not limited in his daily living activities. After 12 weeks, the patient returned to his pre-injury activity level and recreational sports, including mountain biking and hiking. The relative CMS was $93 \%$ with unrestricted full ROM in abduction and flexion, and slight remaining decrease in strength and internal rotation. Clinical examination showed a recurring prominence of the medial clavicle without any signs of instability on palpation. Radiographs indicated a 5-mm superior displacement of the medial clavicle (Figure 4) with the midshaft clavicle fracture healed and satisfactory plate positioning. Due to patient's satisfaction and excellent shoulder function, no further surgical treatment was indicated.

\section{DISCUSSION}

Due to the extreme rarity of this combined injury, there is insufficient evidence on its treatment. To date, four case reports of concomitant anterior SC joint dislocation and ipsilateral midshaft fracture of the clavicle have been reported in the literature in which all cases were treated surgically. ${ }^{[1-4]}$ The SC joint shows a low congruency and is mainly stabilized by the surrounding ligaments and posterior capsule. ${ }^{[8,9]}$ Conservative treatment of isolated SC joint dislocations shows redislocation up to $100 \% \cdot{ }^{[5]}$ Accordingly, the active patient presenting with this severe concomitant injury was treated surgically. Open reduction provided an excellent exposure for both injuries and interposed soft tissue could be eliminated. In all four cases found in the literature, the injury was caused by road accidents of which three were car accidents and one was a bicycle crash. In the report of Yadav et al. ${ }^{[2]}$ and Thomas and Friedman, ${ }^{[1]}$ none of the patients were wearing a seatbelt and the 
car turned over. The cyclist in the report of Tanlin ${ }^{[3]}$ hit the ground with his right shoulder during a crash. There was no detailed report on the mechanism of the injury in the case of Khalid et al. ${ }^{[4]}$ In two of the cases, closed reduction of the SC joint was attempted unsuccessfully.

Khalid et al. ${ }^{[4]}$ found a very unstable SC joint after reduction and plating of the dislocated medial clavicle fracture. Therefore, they decided to fuse it by denuding the articular surface and filling the joint space with cancellous allograft. The joint was stabilized with non-absorbable sutures. At six months of follow-up, the medial clavicle fracture was fully united, the patient had no pain or instability in the left SC joint, and the function of the shoulder returned to normal with a mild limitation of abduction on the operated side.

Thomas and Friedman ${ }^{[1]}$ could reduce the SC joint without exposure after open reduction and fixation of the clavicle shaft fracture using a 3.5$\mathrm{mm}$ Arbeitsgemeinschaft Osteosynthesefragen (AO)/ Association for the Study of Internal Fixation (ASIF) reconstruction plate. Over the next 12 months, the fracture healed and the SC joint remained reduced and pain-free.

Yadav et al. ${ }^{[2]}$ performed transosseous suture fixation of the SC joint after removing an obstructing part of the intraarticular disc and treated the midshaft clavicle fracture non-operatively. Full activities were resumed at eight weeks. At 12 weeks, the patient was symptomfree with full ROM of the shoulder joint and X-rays showed a stable SC joint and uniting of the midshaft clavicle fracture with persistent angulation.

In addition, one case of a 16-year-old patient who sustained a midshaft clavicle fracture with concurrent SC joint subluxation was reported. ${ }^{[20]}$ This case was the only case managed non-surgically. The injury was sustained during wrestling and only the displaced midshaft clavicle fracture was diagnosed initially, which was treated with a sling. At the follow-up examination after three weeks, a SC joint subluxation and an injury of the long thoracic nerve with scapular winging were diagnosed. Following the non-operative treatment, the patient had free ROM and normal shoulder gridle strength five months after injury.

In conclusion, SC dislocation associated with a midshaft clavicle fracture constitutes a rare injury that occurs mainly after traffic accidents. There is a paucity of literature available, and all reported cases were treated surgically. Accordingly, in our case, surgical treatment restored excellent shoulder function. Open reduction and internal fixation of the clavicle combined with SC joint stabilization using transosseous sutures should be considered in the treatment of this uncommon injury.

\section{Declaration of conflicting interests}

The authors declared no conflicts of interest with respect to the authorship and/or publication of this article.

\section{Funding}

The authors received no financial support for the research and/or authorship of this article.

\section{REFERENCES}

1. Thomas CB Jr, Friedman RJ. Ipsilateral sternoclavicular dislocation and clavicle fracture. J Orthop Trauma 1989;3:355-7.

2. Yadav S, Khanna V, Mukherjee S. Ipsilateral sternoclavicular joint anterior dislocation with fracture of the mid shaft of the clavicle. J Clin Orthop Trauma 2019;10:510-3.

3. Tanlin Y. Ipsilateral sternoclavicular joint dislocation and clavicle fracture. J Orthop Trauma 1996;10:506-7.

4. Khalid N, Elbeshbeshy A, Alsaleh KA, Al-Ahaideb A. Anterior sternoclavicular dislocation associated with clavicular fracture: A case report and review of the literature. Eur J Orthop Surg Traumatol 2013;23 Suppl 2:S179-82.

5. Morell DJ, Thyagarajan DS. Sternoclavicular joint dislocation and its management: A review of the literature. World J Orthop 2016;7:244-50.

6. Nettles JL, Linscheid RL. Sternoclavicular dislocations. J Trauma 1968;8:158-64.

7. Sernandez H, Riehl J. Sternoclavicular joint dislocation: A systematic review and meta-analysis. J Orthop Trauma 2019;33:e251-e5.

8. Spencer EE, Kuhn JE, Huston LJ, Carpenter JE, Hughes RE. Ligamentous restraints to anterior and posterior translation of the sternoclavicular joint. J Shoulder Elbow Surg 2002;11:43-7.

9. Qu YZ, Xia T, Liu GH, Zhou W, Mi BB, Liu J, et al. Treatment of anterior sternoclavicular joint dislocation with acromioclavicular joint hook plate. Orthop Surg 2019;11:91-6.

10. Booth CM, Roper BA. Chronic dislocation of the sternoclavicular joint: An operative repair. Clin Orthop Relat Res 1979;140:17-20.

11. Franck WM, Siassi RM, Hennig FF. Treatment of posterior epiphyseal disruption of the medial clavicle with a modified Balser plate. J Trauma 2003;55:966-8.

12. Bae DS, Kocher MS, Waters PM, Micheli LM, Griffey M, Dichtel L. Chronic recurrent anterior sternoclavicular joint instability: Results of surgical management. J Pediatr Orthop 2006;26:71-4.

13. Abiddin Z, Sinopidis C, Grocock CJ, Yin Q, Frostick SP. Suture anchors for treatment of sternoclavicular joint instability. J Shoulder Elbow Surg 2006;15:315-8.

14. Lyons FA, Rockwood CA Jr. Migration of pins used in operations on the shoulder. J Bone Joint Surg [Am] 1990;72:1262-7.

15. Axelrod DE, Ekhtiari S, Bozzo A, Bhandari M, Johal H. What is the best evidence for management of displaced midshaft 
clavicle fractures? A systematic review and network metaanalysis of 22 randomized controlled trials. Clin Orthop Relat Res 2020;478:392-402.

16. Amer K, Smith B, Thomson JE, Congiusta D, Reilly MC, Sirkin MS, et al. Operative versus nonoperative outcomes of middle-third clavicle fractures: A systematic review and meta-analysis. J Orthop Trauma 2020;34:e6-e13.

17. Böhme J, Bonk A, Bacher GO, Wilharm A, Hoffmann R, Josten $C$. Current treatment concepts for mid-shaft fractures of the clavicle - results of a prospective multicentre study. Z Orthop Unfall 2011;149:68-76.
18. Ropars M, Thomazeau H, Huten D. Clavicle fractures. Orthop Traumatol Surg Res 2017;103(1S):S53-S59.

19. Wang D, Camp CL, Werner BC, Dines JS, Altchek DW. Figure-of-8 reconstruction technique for chronic posterior sternoclavicular joint dislocation. Arthrosc Tech 2017;6:e1749-e1753.

20. Pearsall AW 4th, Russell GV Jr. Ipsilateral clavicle fracture, sternoclavicular joint subluxation, and long thoracic nerve injury: An unusual constellation of injuries sustained during wrestling. Am J Sports Med 2000;28:904-8. 